Prepared for the U.S. Department of Energy

under Contract DE-AC05-76RL01830

\title{
Assessment of Various Types of Uncertainty in the Techa River Dosimetry System
}

BA Napier

MO Degteva

LR Anspaugh

September 2008

Pacific Northwest

NATIONAL LABORATORY

Proudly Operated by Battelle Since 1965 


\title{
DISCLAIMER
}

This report was prepared as an account of work sponsored by an agency of the United States Government. Neither the United States Government nor any agency thereof, nor Battelle Memorial Institute, nor any of their employees, makes any warranty, express or implied, or assumes any legal liability or responsibility for the accuracy, completeness, or usefulness of any information, apparatus, product, or process disclosed, or represents that its use would not infringe privately owned rights. Reference herein to any specific commercial product, process, or service by trade name, trademark, manufacturer, or otherwise does not necessarily constitute or imply its endorsement, recommendation, or favoring by the United States Government or any agency thereof, or Battelle Memorial Institute. The views and opinions of authors expressed herein do not necessarily state or reflect those of the United States Government or any agency thereof.

\author{
PACIFIC NORTHWEST NATIONAL LABORATORY \\ operated by \\ BATTELLE \\ for the \\ UNITED STATES DEPARTMENT OF ENERGY \\ under Contract DE-AC05-76RL01830
}

Printed in the United States of America
Available to DOE and DOE contractors from the Office of Scientific and Technical Information,
P.O. Box 62, Oak Ridge, TN 37831-0062;
ph: (865) 576-8401
fax: $(865)$ 576-5728
email: reports@adonis.osti.gov

\begin{abstract}
Available to the public from the National Technical Information Service, U.S. Department of Commerce, 5285 Port Royal Rd., Springfield, VA 22161 ph: (800) 553-6847 fax: $(703) 605-6900$ email: orders@ntis.fedworld.gov online ordering: http://www.ntis.gov/ordering.htm
\end{abstract}

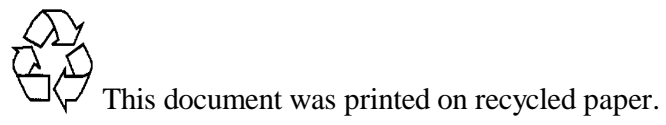


ASSESSMENT OF VARIOUS TYPES OF UNCERTAINTY IN THE TECHA RIVER DOSIMETRY SYSTEM

\author{
B.A. Napier, M.O. Degteva, L.R. Anspaugh
}

\author{
Pacific Northwest National Laboratory \\ Richland, Washington, USA
}

Urals Research Center for Radiation Medicine

Chelyabinsk, Russian Federation

University of Utah

Salt Lake City, Utah, USA

\begin{abstract}
Unscheduled Report
US-Russian Joint Coordinating Committee on Radiation Effects Research Project 1.1:

"Further Studies on Uncertainty and Validation of Doses in the Techa River Dosimetry System"
\end{abstract}

Revision of September 2008 


\section{TABLE OF CONTENTS}

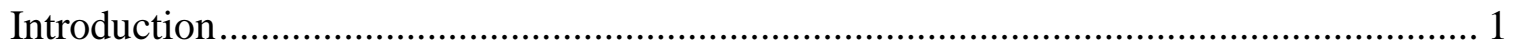

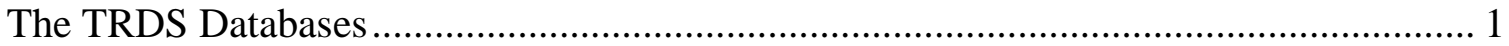

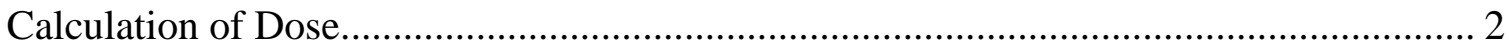

Preliminary Assignment of Uncertainty Types..................................................... 9

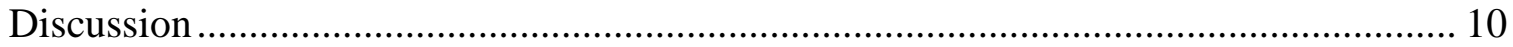

Planned Approach to Uncertainty Propagation.............................................................. 13

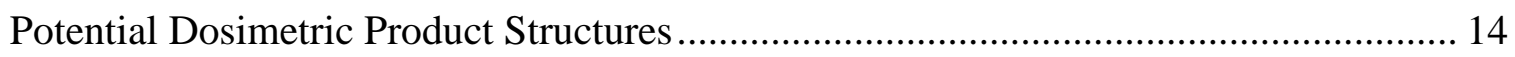

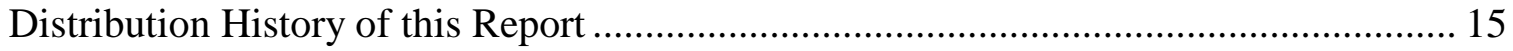

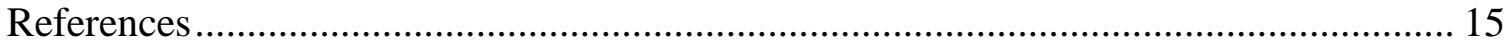

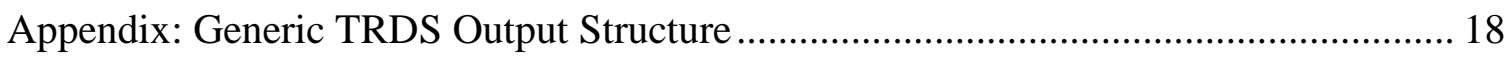




\section{Introduction}

Recent developments in evaluation of dose-response models in light of uncertain dose data (Stram and Kopecky 2003; Schafer and Gilbert 2006) have highlighted the importance of different types of uncertainties in the development of individual dose estimates. These include uncertain parameters that may be either shared or unshared within the dosimetric cohort, and also the nature of the type of uncertainty as either classical or Berkson. This report is an initial attempt to identify the nature of the various input parameters and calculational methods incorporated in the Techa River Dosimetry System (based on the TRDS-2000 implementation as a starting point, with additions for recently-developed capabilities).

This report reviews the database, equations, and input parameters, and then identifies the author's interpretations of their general nature. It closes with some questions for the users of the data (epidemiologists and biostatisticians), so that the next implantation of the TRDS will provide the most useful information.

\section{The TRDS Databases}

The TRDS databases consist of three modules - the first and second modules are "system databases" which contain parameters used in the dose estimation, and the third is "input data" for the calculations. Thus, the first and second are "internal modules" of TRDS, but the third is an "external module." These modules are:

1. An environmental module that contains the following data for each of the Techa Riverside settlements:

- Age-dependent mean annual-intake levels of radionuclides, and

- Mean annual external dose rates in air near the shoreline, outdoors in the residence areas, and indoors.

2. A metabolic module that contains the results of age-dependent model calculations of doses in different organs per unit intake for all radionuclides ingested (dose-conversion factors). 
3. An individual-data module that contains the following information for each of the Extended Techa River Cohort (ETRC) members: identification code, year of birth, year of entry to the epidemiologic catchment area, year of migration from the catchment area, vital status, year of vital status determination, and residence history within the contaminated areas. This third module is prepared and updated by epidemiologists working on companion studies. This module will also contain individual evaluated dosimetric information, linked by the identification code, which indicates the type of internal dose calculation that minimizes the uncertainty of internal dose (discussed further below). This module is the "input data" for the individual doses estimated for the cohort by the TRDS.

These components of the database essentially provide the input data from which the dosimetry system runs.

\section{Calculation of Dose}

The method being used for the TRDS dose calculations is relatively simple and can be written as a single equation in four parts as Equation 1:

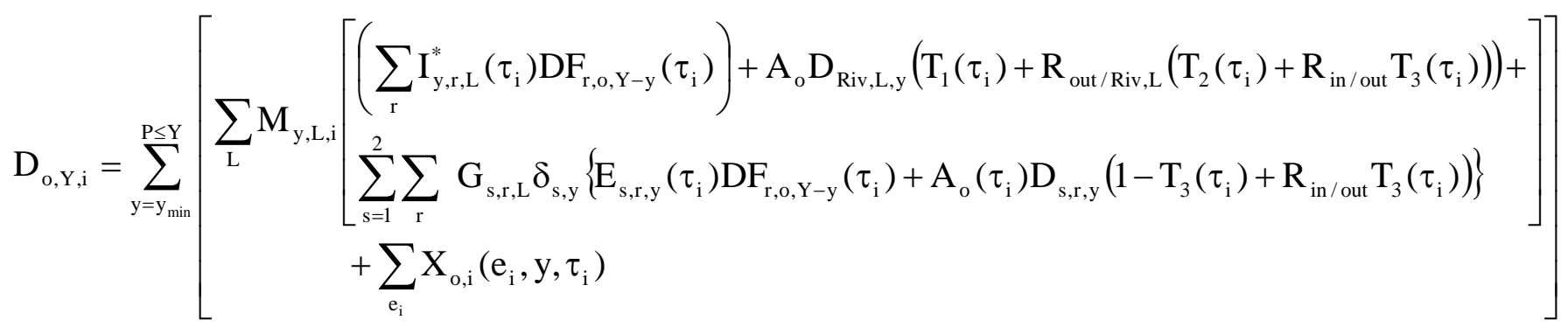

Here the upper line in the internal brackets represents the dose from the Techa River, the middle line represents dose from exposure to fallout from the East Urals Radioactive Trace (EURT) ( from medical x-ray examinations. (Note that doses from ingestion of iodine from Mayak releases are theoretically included in the TRDS, but the parameters will only be calculated and added to the system later). The individual components are:

$D_{o, Y, i}=$ absorbed dose $(\mathrm{Gy})$ in organ $o$ accumulated through calendar year $Y$ to individual $i$; 
$Y \quad=$ the calculational endpoint for a particular individual (can vary according to the analyst's wishes within the range 1950-2015);

$b_{i} \quad=$ the year of birth of individual $i$;

$y \quad=$ year of environmental exposure (external irradiation and intake of nuclides). The minimum value of $y$ in the summation is $y_{\min }=\operatorname{MAX}\left\{1949, b_{i}\right.$, year of first moving to the Techa River, EURT or KT areas\};

$P \quad=$ the endpoint of external exposure and intake of radionuclides for a particular individual (can vary within the range $1950-Y, P \leq Y$ ).

$L \quad=$ location (settlement) identifier;

$M_{y, L, i}=$ fraction of year $y$ spent in location $L$ by individual $i$;

$r \quad=$ identifier of ingested radionuclide $\left({ }^{89} \mathrm{Sr},{ }^{90} \mathrm{Sr},{ }^{95} \mathrm{Zr},{ }^{95} \mathrm{Nb},{ }^{103} \mathrm{Ru},{ }^{106} \mathrm{Ru},{ }^{137} \mathrm{Cs},{ }^{141} \mathrm{Ce}\right.$, ${ }^{144} \mathrm{Ce}$ or $\left.{ }^{131} \mathrm{I}\right)$;

$\tau_{i} \quad=y-b_{i}$, the age of individual $i$ in year $y$ (years);

$I_{y, r, L}^{*}=$ intake function $(\mathrm{Bq})$ for year $y$, radionuclide $r$, and location $L$ (function of age $\tau$, related to $y$ );

$I^{*}=I \times \xi_{i}$, where $\xi_{i}$ is a modifier predetermined for individual $i$ equal to 1.0 (village average), $I M R_{i}$ (individual to model ratio), or $H S R_{i}$ (household-specific ratio), discussed below;

$D F_{r, o, Y-y}=$ conversion factor $\left(\mathrm{Gy} \mathrm{Bq}^{-1}\right)$ for dose accumulated in organ $o$ in year $Y-y$ from intake of radionuclide $r$ in year $y$ (function of gender and age, related to $y$ );

$Y-y=$ time since intake, years;

$A_{o} \quad=$ conversion factor from absorbed dose in air to absorbed dose in organ $o$ (function of age, related to $y$ );

$D_{R i v, L, y}=$ absorbed dose in air near river shoreline at location $L$ received in year $y(\mathrm{~Gy})$.

$R_{\text {out } R i v, L}=$ ratio of dose rate in air outdoors at homes to the dose rate by the river at location $L$;

$R_{\text {in/out }}=$ ratio of dose rate in air indoors to that outdoors;

$T_{1} \quad=$ time spent on river bank (relative to whole year) (function of age, related to $y$ );

$T_{2} \quad=$ time spent outdoors (relative to whole year) (function of age, related to $y$ );

$T_{3}=$ time spent indoors (relative to whole year) (function of age, related to $y$ ).

$G_{s, r, L}=$ surface deposition $\left(\mathrm{Bq} \mathrm{m}^{-2}\right)$ at location $L$ of radionuclide $r$ from fallout from the $\operatorname{EURT}(s=1)$ or $\operatorname{KT}(s=2)$;

$\delta_{s, y}=0$ or 1 depending on $s$ and $y$. For the EURT $(s=1), \delta_{1, y}=0$ for $y<1957$, and for the $\mathrm{KT}(s=2), \delta_{2, y}=0$ for $y<1967$;

$E_{s, r, y}=$ intake function $\left(\mathrm{Bq}\right.$ per $\mathrm{Bq} \mathrm{m}^{-2}$ ) for year $y$, radionuclide $r$, and fallout source $s$ (EURT or KT), (function of age, related to $y$ ), further described below;

$D_{s, r, y}=$ absorbed dose in air $(\mathrm{Gy})$ received in year $y$ per unit surface deposition of radionuclide $r$ from fallout from the EURT $(s=1)$ or KT $(s=2)$; and 
$X_{o}(e, y, \tau)=$ absorbed dose to organ $o(\mathrm{~Gy})$ from medical examination $e$ in year $y$ for age $\tau$.

The intake function $I_{y, r, L}$ is a complex, time-dependent function derived from a combination of data from tooth beta counting and the whole-body counter. The village-average intake function $I_{y, r, L}$ for each year $y$ is calculated as:

$$
I_{y, r, L}=I_{R}^{S r 90} \times \alpha_{A g e, R}^{S r 90} \times f_{L}^{S r 90} \times R_{y, r / S r}^{L},
$$

where

$I_{R}^{S r 90}=$ Annual ${ }^{90} \mathrm{Sr}$ intake for adult residents of the reference settlement (Muslyumovo);

$\alpha_{A g e, R}^{\text {Sr90 }}=$ Annual ${ }^{90} \mathrm{Sr}$ intake for other age groups relative to that for adults living in the reference settlement;

$f_{L}^{S r 90}=$ Annual ratio of ${ }^{90} \mathrm{Sr}$ intake for location $L$ to ${ }^{90} \mathrm{Sr}$ intake for residents of the reference settlement; and

$R_{y, r / S r}^{L}=$ Annual ratio of radionuclide (r)-to- ${ }^{90} \mathrm{Sr}$ intake for location $L$.

The TRDS calculation of uncertainty will be based on a Monte Carlo approach to implement calculation of the basic dose equation. The required inputs for these analyses have been developed over the course of Project 1.1. The actual results vary depending on the analysis being undertaken, i.e., the specific individual, the particular calculation endpoint year $Y$, organ of interest $o$, and route of exposure (internal or external).

In the basic equation, the parameters $b_{i}, y_{\min }, P, M_{y, L}$, and $\tau$ for each individual come from individual-life-history information and are a series of constants. All of the other parameter values are either calculated or approximated and have associated uncertainty.

It is possible to calculate a village-average intake function for every member of the ETRC. For about half of the cohort, an individual dose based on one or more whole-body counter measurements may be estimated. For these individual dose estimates, the general intake function is normalized by the whole-body count(s). The ratio between the generic estimate and the individual estimate is called the Individual to Model Ratio (IMR). In addition, for many people, IMR values are available for others within their personal household. These may be used to scale the generic intake function for everyone within the family or household, as the average of the household IMR values. This is called a Household-specific Ratio (HSR). Every member of the ETRC.has been evaluated and the best type of intake function (that which minimizes the uncertainty based on use of the whole-body counts through Individual-to-model ratios (IMR), 
Household-specific ratios (HSR), or village averages) has been assigned (Milestone 18 - Shagina et al. 2007); these assignments are available in a database linked to the individual identification code. The advantage of the assignment is that a unique uncertainty distribution is associated with each assignment. Because the HSR are based on dose estimates to other individuals, and all are based on the generic intake function, the order in which the individual dose calculations are performed is important so that necessary cross-references are available.

A recent and stable derivation of the key radionuclide intake term $I_{y, r, L}$ is described in detail in Tolstykh et al. (2001) and updated in Tolstyk et al. (2008). It has a very complex uncertainty structure (Tolstykh et al. 2002; 2008). The variation of intake levels within a single village and age cohort depends mainly on the source of drinking-water supply. In the TRDS2000 system, the village-average WBC-determined body burdens of ${ }^{90} \mathrm{Sr}$ were used to derive the deterministic estimate of accumulated dose. The village average was derived from the entire distribution of measured body burdens of residents of that village. In future versions of the code, an individual's measurements will be used if they are available and appropriate, if not but the individual has measured relatives in the same household, an average will be taken of those, or if neither are available, then the village average will again be used. The relation of the actual measurements to the model predictions is described using Individual-to-Model Ratios (IMR) (Degteva et al. 1999). For a person of age $\tau$ at the beginning of intake and who was measured by $\mathrm{WBC}$ at the year $t_{m}$, the value of IMR is determined as the ratio of an individual-body-burden measurement, $A_{\text {ind }}\left(\tau, t_{m}\right)$, to the value derived from the reference model (representing a permanent resident adult in Muslyumovo), $A_{\bmod }\left(\tau, t_{m}\right)$ :

$$
I M R=A_{\text {ind }}\left(\tau, t_{m}\right)\left[A_{\text {mod }}\left(\tau, t_{m}\right)\right]^{-1} .
$$

In the case of repeated measurements, the value of $I M R$ is determined as the average of all ratios of WBC measurements-to-the respective reference-model values. IMR's serve as age- and timenormalized values that permit the analysis of the entire set of individual data on ${ }^{90} \mathrm{Sr}$ in members of the ETRC.

The uncertainty in intake and retention of ${ }^{90} \mathrm{Sr}$ for any one individual for whom a villageaverage estimate is used is defined by the actual distribution of IMR developed for that village (Degteva et al. 1999). The IMR includes all the TRDS-2000 parameters that go into estimation of term $I_{y, r, L}$, except the location factors $f_{L}$. As defined and presented in Degteva et al. (1999), the IMR is the ratio of the measurement for a specific village to the prediction made as if that 
individual lived in Muslyumovo. Thus, it is necessary to adjust the basic IMR to the specific village by dividing it by the factor $f_{L}^{S r 90}$, defined as the annual ratio of ${ }^{90} \mathrm{Sr}$ intake for location $L$ to ${ }^{90} \mathrm{Sr}$ intake for residents of the reference settlement of Muslyumovo. Thus, the normalized $I M R$ is the ratio of the actual measurements to the model prediction for the specific location. This normalization provides the appropriate magnitude of the range of uncertainty for the predicted intakes.

The normalized IMR's are time-integrated quantities, in that they reflect the deviation of total lifetime intake and retention from that predicted by the TRDS environmental and exposure models. However, it is reasonable to assume that particular individuals would have similar behavior from one year to the next, and that the inter-annual variation is captured in the total normalized IMR. Thus, the distribution of normalized IMR's for each village can be used to estimate the annual distribution of intakes and retentions for residents of that village. Because of these considerations, it is not necessary to model explicitly the various components of drinkingwater source, diet, uptake, or metabolism that go into estimation of the radionuclide-intake term, $I_{y, r, L}$, and this greatly simplifies the uncertainty analyses. The distribution shape and range of the term $I_{y, r, L}$ is defined for each village by the village-specific normalized IMR. The dose to any one individual can vary an order of magnitude up or down from the median-model prediction, when based on the village-average values.

Dose-conversion factors, $D F_{r, o, Y-y}$, are calculated using biokinetic models, and their uncertainties are determined mainly by the variability of metabolic parameters (Shagina et al. 2000). However, for ${ }^{90} \mathrm{Sr}$, the individual variability in uptake and metabolism is actually captured in the IMR values, because the IMR's reflect not only intake but also long-term retention. The remaining uncertainties in the dosimetric model are embodied within the specific effective energy quantity and are associated mainly with variations in masses, shapes and locations of the organ and tissue of the human body and with oversimplifications of the representations of certain complex anatomical structures in the body when calculating the energy deposition (NCRP 1998). Thus, the uncertainty in the dose-conversion component for ${ }^{90} \mathrm{Sr}$ is relatively low. The uncertainties in the dose-conversion factors for other radionuclides are larger, reflecting the lack of available measurements and the potential for individual variations in uptake and retention. Because individual variations in uptake and retention will vary less from year to year than the variation among individuals, the dose-factor variability is held constant 
from year to year for a single realization of the dose estimate and only varied for additional realizations.

One additional uncertainty term is needed for the non- ${ }^{90} \mathrm{Sr}$ radionuclides to address the ratio of intakes of these nuclides to ${ }^{90} \mathrm{Sr}$. This is the term $R_{y, r / S r}^{L}$, the annual ratio of nuclide-to${ }^{90} \mathrm{Sr}$ intake. Because the intakes were primarily from drinking water, the intakes are proportional to the estimated concentrations of these radionuclides in river water. These ratios are currently estimated based on the results of a Techa River Model. Thus, uncertainties in intake are directly proportional to uncertainties in predicted concentrations in river water. Based on the data presented in the one-compartment Techa River transport model, the predicted concentrations could vary by up to $50 \%$ with different selection of transport parameters based on available data. Sensitivity analyses for residents of Muslyumovo indicate that this uncertainty contributes very little to the total uncertainty for dose to red bone marrow, because the internal doses are dominated by the contribution from ${ }^{90} \mathrm{Sr}$. The uncertainties in this term are relatively more important for organs of the gastrointestinal tract, because more of the dose resulted from these other radionuclides.

However, recent rework of the Techa River source term by a combined team of URCRM, Mayak, and US collaborators has greatly refined the temporal resolution of the source term [Degteva et al. 2008]. Additional modeling is required for the period 1951-1952 to adequately describe the dynamics of the water concentration of the various radionuclides. Work is currently underway to do this. As a result, the various parameters described herein will need to be refined to shorter time periods - perhaps to the order of one month for this period. To accommodate this new information, it may be necessary to re-write the equation above with the annual summations replaced by monthly ones. This will increase the workload and database size, but not the overall approach.

In a similar manner, intake functions have been developed for exposures to the EURT and KT fallout. Data Directories of ${ }^{90} \mathrm{Sr}$-contamination density of Urals settlements $\left(G_{s, r, L}\right)$ were created (Tolstykh et al. 2006) with an evaluation of existing data on radionuclide contents in food and the human body that supported development of the necessary input parameters on timeand location-dependent intake rates of radionuclides (Tolstykh et al. 2006). The basic approach considered by Tolstykh et al. (2006) for the reconstruction of internal doses employ conversion factors $E_{s, r, y}$, that is, dose per unit ground deposition $\left(\mathrm{Gy}\right.$ per $\left.\mathrm{kBq} \mathrm{m}^{-2}\right)$. The approach is based 
upon measurements of radionuclides in local foodstuffs. For the purposes of the EURT analysis we consider the intake of long-lived ${ }^{90} \mathrm{Sr}$ up to 1980 , the intake of short-lived radionuclides essentially ended after 1959. For external dose calculations, dose rates in air per unit-deposition density of ${ }^{90} \mathrm{Sr}$ for the EURT area $D_{s, r, y}$ derived by Vorobiova et al. (2006) are used. Dose accumulation is considered for only the two first years after contamination, because dose-rate values decreased rapidly due to radioactive decay of the short-lived radionuclides. For the KT, the period of external dose accumulation is considered the same as for intake with food (19671980). Other parameters of external exposure (such as typical life patterns and shielding, as well as conversion factors from dose in air to dose in organs) are the same as used for Techa River exposure.

The conversion factor from absorbed dose in air to absorbed dose in organ $o, A_{o}$, is a mild function of radiation energy. However, there is a large plateau in the energy-dependent response between about 0.08 and 1.3 MeV (Eckerman and Ryman 1993), the energies of most interest for the radionuclides discharged to the Techa River. There is also a minor variation as a function of body mass for various ages. This parameter will be slightly variable for individuals of different weights.

The terms $T_{1}, T_{2}$, and $T_{3}$, while ideally coming from individual data, are currently assigned generic values, depending on the age of the individual in year $y$. A discussion of various lifestyle surveys is presented in Vorobiova et al. (1999). They are allowed to change from year to year to account for individual circumstances.

The external dose rates, $D_{R i v, L, y}$ and $D_{s, r, y}$,, are derived from measurements, or alternatively, from the radionuclide contents of sediment as calculated from the Techa River transport model. Values for doses at housing locations outdoors and indoors are derived from $D_{R i v, L, y}$ using river-bank-to-residence-area dose-rate ratios and indoor-to-outdoor dose-rate ratios. Extensive efforts have been made to identify the exact house in which each individual lives, thus allowing detailed specification of this distance for each subject.

Doses to the cohort members from medical x-ray examinations have been estimated by Degteva et al. (2008). A detailed record of each exposure exists; in essence, x-ray doses are added to the individual's appropriate annual organ dose summary at the proper time. These individual values of $X_{o}(e, y)$ have an associated uncertainty found in the database. 


\section{Preliminary Assignment of Uncertainty Types}

The planned approach to uncertainty analysis is to use Monte Carlo replications of the basic model, using uncertain input parameters. As noted in Stram and Kopecky (2003), the assumption that each replication of possible dose is a sample from the distribution of possible dose for the study subjects is based upon the adoption of what is known as a subjective Bayesian view of the meaning of incomplete information regarding the determinants of dose. This simply means that parameters in the dosimetry system that are incompletely known are assumed to be random quantities, which follow a subjective probability distribution, agreed upon by the experts who developed the system, conditional upon whatever information was available to the experts.

The recent discussions of the susceptibility of the dose-response derivation to uncertainties in the dose estimates have focused attention on two separate problems; shared versus unshared uncertain parameters, and, more globally, classical versus Berkson error structures.

Careful design of the dosimetry system can help address the issue of shared versus unshared uncertain parameters. Development is planned of realizations of dose such that the same vectors of "environmental parameters" are used for each individual at a particular location and time. (This approach was used, for example, in the Hanford Environmental Dose Reconstruction project doses supplied to the Hanford Thyroid Disease Study).

Again, as noted by Stram and Kopecky (2003), "Berkson error models are realistic only if the characteristics of the study population are considered... One cannot build a dosimetry system that will provide Berkson errors for a single subject independent of the population in which the dosimetry system is applied (at least not if errors in subject-specific input data are to be adequately dealt with)." In the TRDS, it is assumed that "environmental parameters" (generally those that are shared by all individuals across a particular dose realization) have Berkson structure, and those that are specific to the individual (if known) have a classical uncertainty structure. However, in the TRDS, generic models are frequently used to fill in for lack of information about specific individuals; in this case the parameter must be considered to be Berkson in nature.

A preliminary assignment of the uncertainty structure to the various TRDS parameters is given in Table 1. 


\section{Discussion}

The parameters that describe the contamination of the environment in which the subjects live generally have a shared uncertainty. Only inputs that are exclusive to a single individual are unshared; in the TRDS system, there are actually quite few of these. In general, it is assumed that inputs that are themselves the products of models (such as the dose conversion factors) have a shared Berkson uncertainty structure, because they are not really specific to any one individual even if an individual modifying factor is applied (because the individual modifiers are generic to all individuals of this type).

Many inputs are used to define a particular calculation; these are assumed to be constant and invariant. The uncertain, non-control parameter $M_{y, L}$ is common to both internal and external dose estimates. This parameter is derived from the individual's residence history, and should have a minor random uncertainty based on either individual recall or interpretation of tax records, etc. Calculations of radionuclide intake are highly dependent on a series of complex model calculations that are independent of any one individual; thus they are both shared and Berkson, because they are assigned to categories of individuals. The conversion factors from intake to dose are also derived from standardized models, some developed specifically for TRDS (such as the strontium metabolism model); thus, these also have shared Berkson uncertainties. The external doses for the first few years are based on models of source term, radionuclide transport in the river, and dose-rate-per-unit-deposition; thus for this period, the resulting parameters have shared Berkson uncertainties. In the later years, the dose rates in each village are based on actual measurements, and the dose rates at the river's edge have classical uncertainty structure. The estimation of dose at each individual's house is, however, based on a radiation transport model and probably has both an unshared classical (distance measurement related) and shared Berkson (model assignment) component. The dose rates within the homes 
Table 1. Assignment of TRDS parameter uncertainty structures.

\begin{tabular}{|c|c|c|c|}
\hline Parameter & Definition & Sharing & Structure \\
\hline \multicolumn{4}{|c|}{ Constants - used to define individual calculation } \\
\hline$Y$ & $\begin{array}{l}\text { The calculational endpoint for a particular individual (can } \\
\text { vary within the range 1950-2005); }\end{array}$ & Definition of case & Constant \\
\hline$y$ & $\begin{array}{l}\text { Year of environmental exposure (external irradiation and } \\
\text { intake of nuclides); }\end{array}$ & Definition of case & Constant \\
\hline$P$ & $\begin{array}{l}\text { The endpoint of external exposure and intake of } \\
\text { radionuclides for a particular individual (can vary within the } \\
\text { range 1950-1959); }\end{array}$ & Definition of case & Constant \\
\hline$L$ & River-location (village) identifier; & Definition of case & Constant \\
\hline$r$ & Identifier of ingested radionuclide; & Definition of case & Constant \\
\hline$Y-y$ & Time since intake, years; & Definition of case & Constant \\
\hline$e$ & Number of $\mathrm{x}$-ray exposures & Definition of case & Constant \\
\hline$b$ & Individual birthday & Definition of case & Constant \\
\hline \multicolumn{4}{|c|}{ Common to internal and external } \\
\hline$M_{y, L}$ & Fraction of year $y$ spent in location $L$ & Individual/unshared & Classical \\
\hline$G_{s, r, L}$ & $\begin{array}{l}\text { Deposition of radionuclide } \mathrm{r} \text { at location } \mathrm{L} \text { for EURT or KT } \\
\text { fallout }\left(\mathrm{Bq} \mathrm{m}^{-2}\right)\end{array}$ & Shared within village & Classical \\
\hline \multicolumn{4}{|c|}{ Internal dose parameters } \\
\hline \multirow[t]{5}{*}{$I_{y, r, L}$} & $\begin{array}{l}\text { Intake function }\left(\mathrm{Bq} y^{-1} r^{-1}\right) \text { for year } y \text {, radionuclide } r \text {, and } \\
\text { location } L \text { (function of age, related to } y \text { ), further described } \\
\text { below; }\end{array}$ & $\begin{array}{l}\text { Product of the following } \\
\text { parameters }\end{array}$ & \\
\hline & $\begin{array}{l}\text { Annual }{ }^{90} \mathrm{Sr} \text { intake for adult residents of the reference } \\
\text { settlement (Muslyumovo); }\end{array}$ & Shared & Berkson \\
\hline & $\begin{array}{l}\text { Annual }{ }^{90} \mathrm{Sr} \text { intake for other age groups relative to that for } \\
\text { adults living in the reference settlement; }\end{array}$ & Shared within ages & Berkson \\
\hline & $\begin{array}{l}\text { Annual ratio of }{ }^{90} \mathrm{Sr} \text { intake for location } L \text { to }{ }^{90} \mathrm{Sr} \text { intake for } \\
\text { residents of the reference settlement; and }\end{array}$ & Shared within village & Berkson \\
\hline & Annual ratio of radionuclide (r)-to- ${ }^{90} \mathrm{Sr}$ intake for location $L$. & Shared within village & Berkson \\
\hline
\end{tabular}




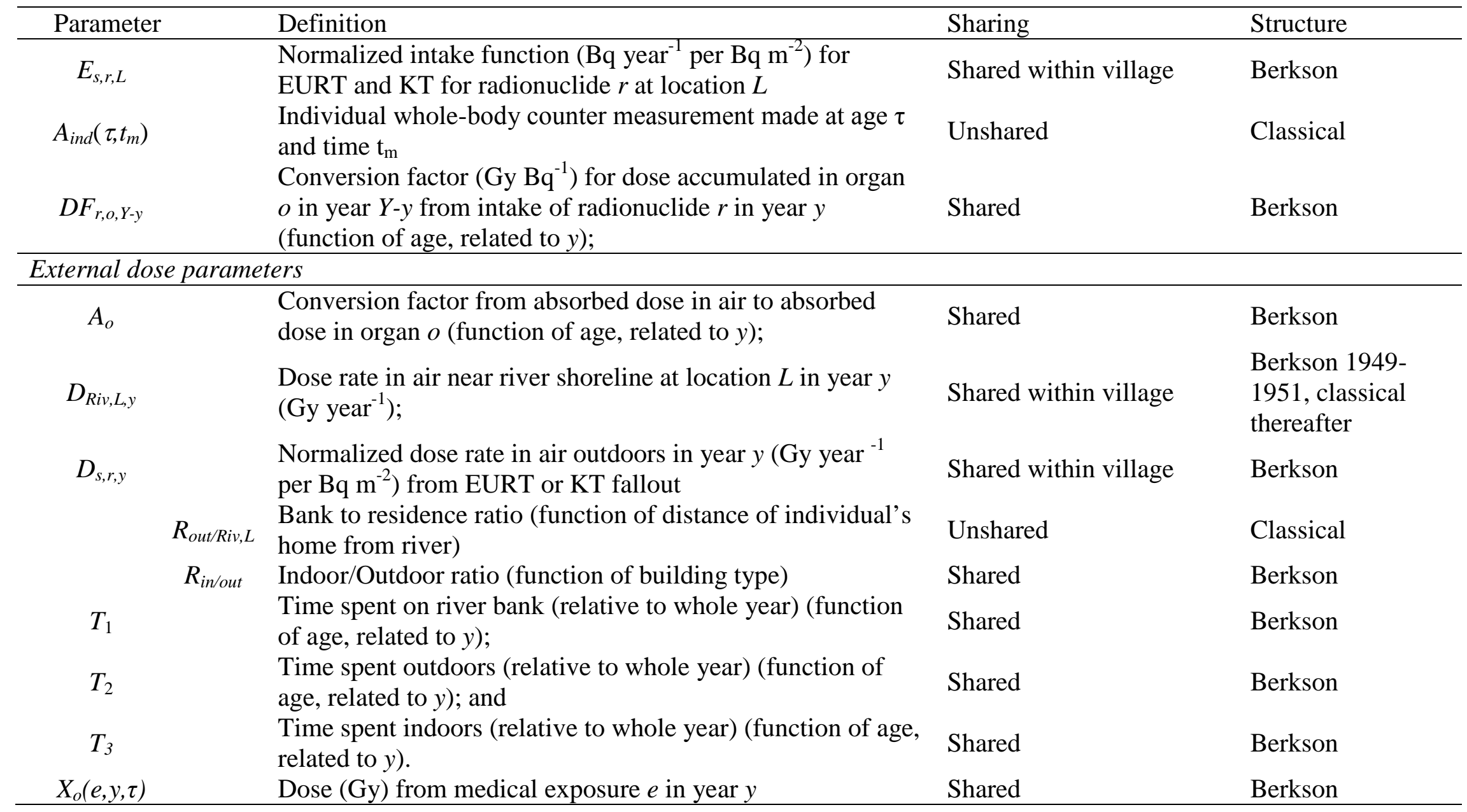


are based on an assigned shielding factor, the distribution of which will again have shared Berkson structure. The exposure times on the river, in the neighborhoods, and in the houses could have unshared classical structure if it were based on individual questionnaire responses, but will usually be assigned from survey results and thus be shared and probably Berkson.

There are correlations between some variables. The terms $R_{y, r / S r}^{L}$ in the internal dose and $D_{\text {riv }}$ in the external dose are the terms in which the uncertain radionuclide "source term" enters the calculation. The structure of the model will have to account for this connection.

\section{Planned Approach to Uncertainty Propagation}

The database processor structure of the current TRDS systems will be helpful in the design of the stochastic dose calculations. There are numerous occurrences of "shared" uncertainties. These largely derive from shared environmental conditions in common residence locations. Thus, in any one realization, people living in a particular village should all see the same conditions at the same time. Water concentrations, external dose rates at the riverbank, and soil concentrations will all be the same for all individuals residing in the same location at the same time. Similarly, those residing in a specified household should all have the same effective shielding factor $\left(R_{\text {in/out }}\right)$. Thus, the databases of environmental information will be pre-calculated as multiple realizations of the possible values.

The relatively limited individual information is unshared. Multiple realizations of doses will be estimated - each will used one of the precalculated sets of environmental data and a random selection of the appropriate unshared stochastic parameters, such as relate to individual behavior or metabolism $\left(T_{1}, T_{2}, T_{3}\right.$, and $D F$ or $\left.A_{\text {ind }}\left(\tau, t_{m}\right)\right)$.

This general structure was used in the Hanford Environmental Dose Reconstruction Project (Ferris et al. 1995; Gilbert et al. 1993) with success.

While such a calculation could conceivably be made with the existing TRDS system, copied and subtly adjusted 100 or 1000 times, it may be more economical, practical, and qualitytraceable to independently re-code and verify the algorithms in a faster, automated program. 


\section{Potential Dosimetric Product Structures}

The plan for application of the stochastic TRDS system, when it is complete, is to generate numerous realizations (one hundred to several thousand) of sequential annual organ absorbed dose for every cohort member. In the original conception, this set of outputs would be transferred to the epidemiologists as an input to the dose-response analyses. The individual output vectors would embody the overall uncertainty of the doses; the outputs could be mathematically manipulated to provide mean, median, geometric standard deviation, or other desired statistical parameters. However, this naive set of outputs would incorporate all shared, unshared, classical, and Berkson uncertainties, because individual dose realizations for every member of the cohort would include the same "shared" data.

As noted above, proper implementation of the dosimetric calculation should appropriately account for shared uncertainties, such that the same realization of dose for every individual would use the same set of shared input parameters. Unshared parameters would be randomly used within each vector for each individual.

However, this approach combines the classical and Berkson components.

One potential option is that the results for selected categories of subjects could be used for sensitivity analyses. The relative contributions of various input parameters to the overall variance could be determined, and these results combined to state that some fraction of the variance, $v$, was contributed by the classical uncertainties and the remaining fraction (1-v) was contributed by the Berkson uncertainties.

As another option, it would be reasonably easy to replicate the calculations (or perform subsets of the entire number of realizations) with specific parameters set as constants to their mean values. If the classical uncertainties were allowed to vary while the Berksons were held constant, a set of realizations might be generated from which a geometric standard deviation $G S D_{C}$ could be generated; similarly, if the Berkson uncertainties were allowed to vary while the classically-distributed parameters where held constant, a related $G S D_{B}$ could be generated. There ought to be some relationship between these statistics and the $\xi$ parameter described above.

The Health Physicist untrained in the intricacies of epidemiological biostatistics is not sure which, if any, of these options might prove to be the most useful to the dose-response analyst. 
Suggestions are appreciated; the consensus on the approach will be used in the design of the calculations.

We are also following with interest the activities by others in dealing with the analysis of uncertainty in dosimetry and its transfer to the dose-response derivation, e.g., Stayner et al. (2007). The approach described above is directly compatible with the Stayner et al. methods.

\section{Distribution History of this Report}

This report was originally prepared prior to the JCCRER International Meeting in Las Vegas of November 2007. At that time, it was shared and discussed within the JCCRER Project 1.1 team and with those epidemiologists and biostatisticians present who are familiar with Projects 1.1 and $1.2 \mathrm{~b}$. It has since been expanded to include the potential confounding pathways of medical x-ray, and the EURT and KT, exposures for conceptual completeness. The recent improvement of knowledge about the Techa River source term (e.g., Degteva et al. 2008) adds computational complexity, but does not alter the basic structure proposed. The most recent update incorporates suggestions from reviewers to the basic equation (1) and some of the definitions.

\section{References}

Degteva, MO, Anspaugh LR, Napier BA, Tolstykh EI, Shagina NB, Kozheurov VP, Vorobiova MI, Tokareva EE, Shishkina EA. Analysis of the main factors contributing to uncertainty in internal dose from ${ }^{90} \mathrm{Sr}$ and feasibility evaluation for reduction in uncertainty.

Chelyabinsk: Urals Research Center for Radiation Medicine; Final Report for Milestone 8; (1999).

Degteva MO, Vorobiova MI, Shagina NB, Shishkina EA, Anspaugh LR, Napier BA. A Review of Data on Releases of Radioactive Wastes from the "Mayak" Production Association into the Techa River In 1949-1956. Chelyabinsk: Urals Research Center for Radiation Medicine; Appendix to Quarterly Report of ISTC Project No.2841 ( January 2008).

Eckerman KF, Ryman JC. External exposure to radionuclides in air, water, and soil. Washington: U.S. Environmental Protection Agency; Federal Guidance Report No. 12, EPA 402-R-93-081; (1993).

Farris WT, Napier BA, Ikenberry TA, Shipler DB. "Radiation Doses from Hanford Site Releases",Health Physics 71:588-601; (1995).

Gilbert RO, Simpson JC, Napier BA, Haerer HA, Liebetrau AM, Ruttenbur AJ, Davis S. 
"Statistical Aspects of the Hanford Environmental Dose Reconstruction Project and the Hanford Thyroid Disease Study", J. Radiation Research 124:354-355; (1993).

Kozheurov VP, Degteva MO. Dietary intake evaluation and dosimetric modelling for the Techa river residents based on in vivo measurements of strontium-90 in teeth and skeleton. Sci. Total Environ. 14:63-72; (1994).

National Council on Radiation Protection and Measurements (NCRP). Evaluating the reliability of biokinetic and dosimetric models and parameters used to assess individual doses for risk assessment purposes. Bethesda: NCRP; Commentary No. 15; (1998).

Schafer DW, Gilbert ES. Some Statistical Implications of Dose Uncertainty in Radiation DoseResponse Analyses, Radiat Res. 166, 303-312 (2006).

Shagina NB, Degteva MO, Tolstykh EI. Uncertainty analysis of strontium retention in humans resulting from individual variability in metabolic parameters. In: Harmonization of radiation, human life and the ecosystem, Proceedings of $10^{\text {th }}$ International Congress on Radiation Protection. Hiroshima, Japan, May 14-19, 2000. Hiroshima: International Radiation Protection Association; CD-ROM, Paper No. P-3a-128; (2000).

Shagina NB, Degteva MO, Tolstykh EI, Zalyapin VI, Krivoshchapov VA, Tokareva EE, Anspaugh LR, Napier BA. Algorithm for Selection of the Best Individual Estimate of Internal Dose on the Basis of the Results of Calculations Performed with use of Three Different Protocols. Chelyabinsk: Urals Research Center for Radiation Medicine; Final Report for Milestone 18; (2007).

Stayner L, Vrijheid M, Cardis E, Stram D, Deltour I, Gilbert S, Howe G. Monte Carlo maximum likelihood methods for estimating uncertainty arising from shared errors in exposures in epidemiological studies. Radiat Res. 168, 757-763 (2007).

Stram DO, Kopecky KJ. Power and uncertainty analysis of epidemiological studies of radiationrelated disease risk in which dose estimates are based on a complex dosimetry system: some observations, Radiat Res. 160, 408-417 (2003).

Tolstykh EI, Zalyapin VI, Krivoshchapov VA, Shagina NB, Peremyslova LM, Degteva MO, Kozheurov VP, Safronova NG, Anspaugh LR, Napier BA. Verification of referent-intake levels for strontium-90. Chelyabinsk and Salt Lake City: Urals Research Center for Radiation Medicine and University of Utah; Final report for Milestone 3 Part 1; September 2001 (in Russian and English).

Tolstykh EI, Zalyapin VI, Shagina NB, Krivoshchapov VA, Degteva MO, Tokareva EE, Anspaugh LR, Napier BA. Estimation of individual-to-model ratios (IMR) and their uncertainty for the Techa River residents. Chelyabinsk and Salt Lake City: Urals Research Center for Radiation Medicine and University of Utah; Final report for Milestone 4; November 2002 (in Russian and English).

Tolstykh EI, Shagina NB, Peremyslova LM, Degteva MO, Anspaugh LR, Napier BA. Methodological approaches to the reconstruction of radionuclide intake for residents of the East Urals Radioactive Trace and Karachay Trace. Chelyabinsk and Salt Lake City: Urals Research Center for Radiation Medicine and University of Utah; Final report for Milestones 11 and 12; April 2006. 
Vorobiova MI, Degteva MO, Kozyrev AV, Anspaugh LR, Napier BA. External doses evaluated on the basis of the Techa River Dosimetry System Approach. Final report for Milestone 6. Chelyabinsk: Urals Research Center for Radiation Medicine; May 1999. 


\section{Appendix: Generic TRDS Output Structure}

There are several options for the general structure of the dosimetry output file. These are minor variations depending on what the "clients" using the information find most convenient. A subsidiary question is the exact breakdown of the doses (internal, external, by source [Techa, EURT, KT, x-ray], total). These options are presented for the purpose of stimulating discussion and agreement.

The first option would have the following structure, by individual:

\section{Individual 1: \\ Total Dose:}

Realization 1:

Organ 1: Year 1, Year 2, Year 3,... Absorbed dose in Gy

Organ 2: Year 1, Year 2, Year 3,...

Organ n: Year 1, Year 2, Year 3,...

Realization 2:

Organ 1: Year 1, Year 2, Year 3, ... Absorbed dose in Gy

Organ 2: Year 1, Year 2, Year 3,...

Organ n: Year 1, Year 2, Year 3,...

Realization n:...

\section{Internal Dose:}

Realization 1:

Organ 1: Year 1, Year 2, Year 3,... Absorbed dose in Gy

Organ 2: Year 1, Year 2, Year 3,...

Organ n: Year 1, Year 2, Year 3,...

Realization 2:

Organ 1: Year 1, Year 2, Year 3,... Absorbed dose in Gy

Organ 2: Year 1, Year 2, Year 3,...

Organ n: Year 1, Year 2, Year 3,...

Realization n:...

\section{External Dose:}

Realization 1:

Organ 1: Year 1, Year 2, Year 3,... Absorbed dose in Gy

Organ 2: Year 1, Year 2, Year 3,...

Organ n: Year 1, Year 2, Year 3,...

Realization 2:

Organ 1: Year 1, Year 2, Year 3,... Absorbed dose in Gy

Organ 2: Year 1, Year 2, Year 3,...

Organ n: Year 1, Year 2, Year 3,...

Realization $\mathrm{n}: . .$.

\section{Individual 2:}

Total Dose:

Realization 1:

Organ 1: Year 1, Year 2, Year 3, ... Absorbed dose in Gy 
Organ 2: Year 1, Year 2, Year 3, ...

Organ n: Year 1, Year 2, Year 3,...

Realization 2:

Organ 1: Year 1, Year 2, Year 3,... Absorbed dose in Gy

Organ 2: Year 1, Year 2, Year 3,...

Organ n: Year 1, Year 2, Year 3,...

Realization $\mathrm{n}$ :...

\section{Internal Dose:}

Realization 1:

Organ 1: Year 1, Year 2, Year 3,... Absorbed dose in Gy

Organ 2: Year 1, Year 2, Year 3,...

Organ n: Year 1, Year 2, Year 3,...

Realization 2:

Organ 1: Year 1, Year 2, Year 3, ... Absorbed dose in Gy

Organ 2: Year 1, Year 2, Year 3,...

Organ n: Year 1, Year 2, Year 3,...

Realization n:...

\section{External Dose:}

Realization 1:

Organ 1: Year 1, Year 2, Year 3, ... Absorbed dose in Gy

Organ 2: Year 1, Year 2, Year 3,...

Organ n: Year 1, Year 2, Year 3,...

Realization 2:

Organ 1: Year 1, Year 2, Year 3,... Absorbed dose in Gy

Organ 2: Year 1, Year 2, Year 3,...

Organ n: Year 1, Year 2, Year 3,...

Realization $\mathrm{n}: . .$.

In this structure, all input parameters $\{a, b, c \ldots\}$ that are "shared" use value $\{a 1, b 1, c 1 \ldots\}$ in realization 1 , value $\{\mathrm{a} 2, \mathrm{~b} 2, \mathrm{c} 2 \ldots\}$ in realization 2 , etc. "Unshared" parameters are randomly selected for each individual in realization 1,2 , etc.

Alternatively, with minimal processing, the structure could be by realization:

\section{Individual 1:}

Total Dose: Realization 1:

Organ 1: Year 1, Year 2, Year 3,... Absorbed dose in Gy

Organ 2: Year 1, Year 2, Year 3,...

Organ n: Year 1, Year 2, Year 3,...

Individual 2:

Total Dose: Realization 1:

Organ 1: Year 1, Year 2, Year 3,... Absorbed dose in Gy

Organ 2: Year 1, Year 2, Year 3, ...

Organ n: Year 1, Year 2, Year 3,...

\section{Individual n:}




\section{Individual 1:}

Total Dose: Realization 2:

Organ 1: Year 1, Year 2, Year 3, ... Absorbed dose in Gy

Organ 2: Year 1, Year 2, Year 3, ...

Organ n: Year 1, Year 2, Year 3, ...

Individual 2:

Total Dose: Realization 2:

Organ 1: Year 1, Year 2, Year 3,... Absorbed dose in Gy

Organ 2: Year 1, Year 2, Year 3, ...

Organ n: Year 1, Year 2, Year 3,...

In this structure, it is again possible to include separately the dose breakdown by type (internal, external, by source [Techa, EURT, KT, x-ray], total) as requested. 